\title{
Single lung alveolar volume and gas transfer: effect of expansion of the other lung
}

\author{
Bjørn Johansen, Øystein Bjørtuft
}

\begin{abstract}
Background - Temporary occlusion of one mainstem bronchus permits measurement of single lung function. A previous study suggested that the volume at which one lung is occluded may influence the expansion of the other. The effect of ipsilateral occlusion volume on the contralateral effective alveolar volume (VA, EFF,SL), inspired volume (VI,SL), single breath estimated residual volume (RVSB,SL), carbon monoxide (CO) transfer (TLCO,SL) and transfer coefficient (KCO,SL) has been examined.

Methods - Single breath measurements of CO transfer were made in duplicate in 12 healthy subjects aged 19-44 years, without and during occlusion of one mainstem bronchus by a balloon at RV and at total lung capacity (TLC).

Results - Mean VA,EFF,SL, VI,SL, and TLCO,SL were lower during occlusion at RV than during occlusion at TLC $(2.84 v$ 3.26 1; $2.18 v 2.541$; and $4.70 v 5.51 \mathrm{mmol}$ $\mathrm{kPa} / \mathrm{min}$ respectively). RVSB,SL was independent of occlusion volume and KCO,SL not different from the KCO of both lungs (KCO,BL). Single lung values during occlusion at TLC were fairly reproducible and were, except for KCo,SL, approximately half the values for both lungs. During occlusion at RV the second TLCO,SL and KCo,SL were lower than the first.

Conclusions - Occlusion of one lung permits reliable determinations of gas transfer indices of the other, provided the lung is occluded at TLC. Occlusion at RV significantly reduces VA,EFF,SL, and hence TLCO,SL, but does not affect KCO,SL of the other lung.
\end{abstract}

(Thorax 1994;49:1238-1242)

Department of Thoracic Medicine, Rikshospitalet, The National Hospital, University of Oslo, N-0027 Oslo, Norway B Johansen

$\emptyset$ Bjørtuft

Reprint requests to: Dr B Johansen.

Received 9 September 1993 Returned to authors 24 November 1993 Revised version received 22 June 1994 Accepted for publication 19 September 1994
In a previous study we occluded one mainstem bronchus at total lung capacity (TLC) and measured static volumes of the other lung by gas dilution. ${ }^{1}$ The residual volume (RV) of the latter was higher than expected, suggesting that the hyperinflated occluded lung prevented the emptying of the other. This finding made us wonder if unilateral occlusion of a deflated lung - that is, at RV - could affect the expansion of the other lung. To further explore the occlusion technique, but avoid longlasting occlusion at $\mathrm{RV}$, we used the single breath carbon monoxide (CO) transfer test ${ }^{2}$ to study the role of unilateral occlusion volume. This method includes the inhalation from RV to TLC of a test gas containing helium and carbon monoxide. The dilution of helium during breathholding permits calculation of the effective alveolar volume (VA,EFF), ${ }^{3}$ which in health is similar to TLC, ${ }^{4}$ and which is a prerequisite for the calculation of the transfer factor (TLCO).

Intra-individual variations in preinspiratory lung volume before the test gas is inhaled have no effect on gas transfer. ${ }^{5}$ Variations in end inspiratory volume during breathholding, however, are positively related to TLCo. ${ }^{6-8}$ Furthermore, the transfer coefficient (KCO), or TLCO/VA,EFF, is inversely related to end inspiratory volume. ${ }^{3910}$ If unilateral occlusion at RV decreases TLC - that is, VA,EFF of the other lung - TLCO of that lung should also decrease and Kco increase. In contrast, occlusion at TLC should not affect gas transfer even if RV of the other lung increases. The purpose of this study was (1) to measure single breath gas transfer of one lung during occlusion of the other, and (2) to test the hypothesis that the volume at which occlusion takes place determines the filling of the other lung.

\section{Methods}

SUBJECTS

Seven male and five female healthy volunteers aged 19-44 years, smokers and non-smokers, participated in this study. They had no history of respiratory or cardiac disease or recent airway infection, nor had they any clinical signs of airways obstruction. Their ventilatory lung function was within normal limits as determined by dynamic spirometry on the day of investigation. ${ }^{11}$ One additional woman was examined but excluded due to persistent cough during the initial bronchoscopy. Each subject was carefully informed about the purpose and the content of the study, both verbally and in writing. All gave written informed consent to participate. The study was approved by the Regional Health Area ethical committee.

\section{AIRWAY OCCLUSION}

The mainstem bronchus was occluded by the inflatable balloon of an $80 \mathrm{~cm}$ long Fogarty venous thrombectomy catheter, size 8/10 French (American Edwards Laboratories, Santa Ana, California, USA). The balloon had a maximum diameter of $19 \mathrm{~mm}$ and a maximum capacity of $4 \mathrm{ml}$. The catheter was advanced transnasally into the mainstem bronchus under guidance of a paediatric fibreoptic bronchoscope (Olympus BF OC10) during topical anaesthesia with nebulised oxybu- 
procaine. The subjects were premedicated with atropine, diazepam, and dihydrocodeinone. Other details of the insertion procedure were as described in the previous paper. $^{1}$

With the deflated balloon in one mainstem bronchus, the seated subjects either inhaled or exhaled as completely as possible and then held their breath. The balloon was inflated rapidly with saline until it occluded the airway completely. The position of the balloon was checked during one or two tidal breaths before deflating it and the inflation/deflation procedure was repeated if necessary to adjust its position and volume of fluid. The catheter with deflated balloon was fixed to the nostril, the bronchoscope removed, and the subjects placed in another chair in front of the transfer test apparatus. At that time they had been seated for at least 30 minutes.

\section{GAS TRANSFER MEASUREMENTS}

The single breath transfer factor was measured with a Gould automated system 2400 (Sensormedics BV, Bilthoven, The Netherlands) and according to guidelines recommended by the European Community for Coal and Steel (ECCS). ${ }^{12}$ The test gas mixture was composed of $0.29 \%$ carbon monoxide, $9.41 \%$ helium, $19 \cdot 3 \%$ oxygen, and a balance of nitrogen. It was inhaled after a maximal expiration and allowed to dilute and/or diffuse during breathholding in maximal inspiration. The first $750 \mathrm{ml}$ of the expirate was discarded and the next $750 \mathrm{ml}$ sampled in a bag and analysed for carbon monoxide and helium. VA,EFF was calculated from the corrected dilution of helium and the inspired volume (VI). Anatomical (see below) and instrumental dead space $(85 \mathrm{ml})$ were subtracted from VI before VA,EFF was calculated. The concentration of expired helium was divided by 1.05 to correct for absorption of carbon dioxide before helium analysis. The single breath estimate of RV (RVSB) was defined as VA,EFF minus VI. VA,EFF in litres BTPS was used to calculate TLCO, and Kco was calculated as TLCo/VA,EFF. Anatomical deadspace was $150 \mathrm{ml}$ without occlusion and $115 \mathrm{ml}$ when one lung was studied. ${ }^{13}$ Breathholding was preset to 10 seconds, and the effective duration of breathholding derived as recommended. ${ }^{14} \mathrm{Hae}-$ moglobin and carboxyhaemoglobin levels were not measured. The subjects were studied at sea level. Reference values were those of ECCS. ${ }^{12}$

STUDY PROTOCOL

Whole lung function, as measured at the mouth, was recorded in three consecutive circumstances: (a) with the balloon deflated; (b) with mainstem bronchus of one lung occluded at RV; and (c) with the same lung occluded at TLC. To minimise the effect of volume history ${ }^{15}$ the subjects made two or three tidal breaths, also when one lung was occluded, before they exhaled to RV and rapidly breathed in the test gas. In all circumstances measurements were made in duplicate with a five minute interval between each replicate. The mainstem bronchus was never occluded for more than 30 seconds at a time. The subjects remained seated during the whole session. Oxygen saturation was recorded throughout the procedure with a pulse oximeter (Minolta Pulsox-7).

\section{RANDOMISATION AND DATA ANALYSIS}

The lung to be occluded was selected at random for each subject, but we had already decided to examine six right and six left lungs. The sequence of measurement when the mainstem bronchus was occluded at either TLC, RV, or not at all was randomised for each subject according to a complete block design. The statistical package SPSS (version $4 \cdot 0$ ) was used for data entry and analysis. The measurement error was defined as the standard deviation of a single determination (standard deviation of the difference between duplicate values divided by the square root of 2), and repeatability as the coefficient of variation. Mean values were compared with the two tailed paired and two sample $t$ test, and considered to be significantly different if the $p$ value was $<0 \cdot 05$. Relations between continuous variables were examined by Pearson's correlation coefficient. If systematic differences between replicates were found, the value of the first was used for further analysis, otherwise the average of duplicate values was used.

\section{Results}

\section{PRECISION}

Table 1 shows that without occlusion and during occlusion at TLC no systematic differences between replicates were found except that the second RVsB,BL was lower than the first $(1 \cdot 27$ $v 1.341, \mathrm{p}<0 \cdot 01)$. In contrast, when occlusion took place at $\mathrm{RV}$, the second replicates of RVsB,SL, TLCo,SL, and KCo,SL of the nonoccluded lung were significantly lower than the first. The smaller second RVsB,SL was accompanied by a somewhat larger VI,SL, making the first and second VA,EFF,SL identical. Table 1 also shows that the measurement errors of single lung variables did not differ much from those of the whole lung, but that the coefficient of variation was twice as large.

\section{COMPARISON BETWEEN SINGLE AND BOTH \\ LUNGS}

The individual values of TLCo (average of replicates) for both lungs and for one lung during occlusion at TLC are listed in table 2 . The mean TLCo for both lungs was $11 \cdot 00$, and for a single lung $5.36 \mathrm{mmol} / \mathrm{kPa} / \mathrm{min}$. There was no difference between the absolute values of the right and left lung. However, the ratio of the right TLCO,SL to TLCO,BL was significantly larger than that of the left to the whole lung $(0.55 v 0.44 ; \mathrm{p}<0.05$, two sample $t$ test). The table also shows that the ratio of the right VA,EFF,SL to VA,EFF,BL was larger than that of the left to the whole lung $(0.57 v 0.50, \mathrm{p}<0.05)$. There was a correlation between the ratio of 
Table 1 Duplicate group mean values and measurement error of whole and single lung gas transfer components in 12 healthy volunteers

\begin{tabular}{|c|c|c|c|c|c|c|c|}
\hline $\begin{array}{l}\text { Occlusion } \\
\text { volume }\end{array}$ & Variable & $\begin{array}{l}\text { First } \\
\text { test }\end{array}$ & $\begin{array}{l}\text { Second } \\
\text { test }\end{array}$ & $S E D$ & $p$ & $S D S D$ & $\begin{array}{l}C V \\
(\%)\end{array}$ \\
\hline $\begin{array}{l}\text { None } \\
\text { None } \\
\text { None } \\
\text { None } \\
\text { None }\end{array}$ & $\begin{array}{l}\text { VA,EFF,BL } \\
\text { VI,BL } \\
\text { RVSB,BL } \\
\text { TLCO,BL } \\
\text { KCO,BL }\end{array}$ & $\begin{array}{r}6.22 \\
4 \cdot 88 \\
1 \cdot 34 \\
10.91 \\
1 \cdot 76\end{array}$ & $\begin{array}{r}6 \cdot 20 \\
4.92 \\
1 \cdot 27 \\
11 \cdot 09 \\
1 \cdot 78\end{array}$ & $\begin{array}{l}0.032 \\
0.029 \\
0 \cdot 021 \\
0 \cdot 196 \\
0.032\end{array}$ & $\begin{array}{l}\text { NS } \\
\text { NS } \\
<0 \cdot 01 \\
\text { NS } \\
\text { NS }\end{array}$ & $\begin{array}{l}0.08 \\
0.07 \\
\text { NA } \\
0.48 \\
0.08\end{array}$ & $\begin{array}{c}1.2 \\
1.4 \\
\mathrm{NA} \\
4.4 \\
4.5\end{array}$ \\
\hline $\begin{array}{l}\text { TLC } \\
\text { TLC } \\
\text { TLC } \\
\text { TLC } \\
\text { TLC }\end{array}$ & $\begin{array}{l}\text { VA,EFF,SL } \\
\text { VI,SL } \\
\text { RVSB,SL } \\
\text { TLCO,SL } \\
\text { KCO,SL }\end{array}$ & $\begin{array}{l}3.26 \\
2.54 \\
0.72 \\
5.51 \\
1.69\end{array}$ & $\begin{array}{l}3 \cdot 26 \\
2 \cdot 54 \\
0 \cdot 72 \\
5 \cdot 20 \\
1 \cdot 59\end{array}$ & $\begin{array}{l}0.041 \\
0.036 \\
0.020 \\
0.021 \\
0.054\end{array}$ & $\begin{array}{l}\text { NS } \\
\text { NS } \\
\text { NS } \\
\text { NS } \\
\text { NS }\end{array}$ & $\begin{array}{l}0.11 \\
0.09 \\
0.05 \\
0.54 \\
0.07\end{array}$ & $\begin{array}{r}3 \cdot 1 \\
3 \cdot 4 \\
6 \cdot 7 \\
10 \cdot 1 \\
4 \cdot 2\end{array}$ \\
\hline $\begin{array}{l}\text { RV } \\
\text { RV } \\
\text { RV } \\
\text { RV } \\
\text { RV }\end{array}$ & $\begin{array}{l}\text { VA,EFF,SL } \\
\text { VI,SL } \\
\text { RVSB,SL } \\
\text { TLCO,SL } \\
\text { KCO,SL }\end{array}$ & $\begin{array}{l}2 \cdot 84 \\
2 \cdot 14 \\
0 \cdot 70 \\
4 \cdot 70 \\
1 \cdot 65\end{array}$ & $\begin{array}{l}2 \cdot 84 \\
2 \cdot 23 \\
0 \cdot 62 \\
4 \cdot 18 \\
1 \cdot 46\end{array}$ & $\begin{array}{l}0.044 \\
0.052 \\
0.037 \\
0.186 \\
0.047\end{array}$ & $\begin{array}{l}\text { NS } \\
\text { NS } \\
<0.05 \\
<0.02 \\
<0.005\end{array}$ & $\begin{array}{l}0 \cdot 11 \\
0 \cdot 13 \\
\text { NA } \\
\text { NA } \\
\text { NA }\end{array}$ & $\begin{array}{l}3 \cdot 8 \\
5 \cdot 8 \\
\text { NA } \\
\text { NA } \\
\text { NA }\end{array}$ \\
\hline
\end{tabular}

$\mathrm{VA}, \mathrm{EFF}=$ effective alveolar volume; $\mathrm{VI}=$ inspired volume; $\mathrm{RVSB}=$ single breath residual volume; $\mathrm{TLCO}=$ transfer factor; $\mathrm{KcO}=$ transfer coefficient; SED = standard error of the difference between means; SDSD = standard deviation of a single determination (measurement error); $\mathrm{CV}=$ coefficient of variation; $\mathrm{NS}=$ not significant; $\mathrm{NA}=$ not applicable; $\mathrm{BL}=\mathrm{both}$ lungs; $\mathrm{SL}=\mathrm{single}$ lung. Volumes are expressed in litres BTPS, TLCo in $\mathrm{mmol} / \mathrm{min} / \mathrm{kPa}$, and $\mathrm{KCO}$ in $\mathrm{mmol} / \mathrm{min} / \mathrm{kPa} / \mathrm{l}$.

Table 2 Predicted and observed transfer factor (TLCO) of both lungs and of a single lung during occlusion at TLC, and the ratios of single to both lung transfer factor and effective alveolar volume in 12 healthy volunteers

\begin{tabular}{|c|c|c|c|c|c|c|}
\hline $\begin{array}{l}\text { Subject } \\
\text { no. }\end{array}$ & $\begin{array}{l}\text { Examined } \\
\text { lung }\end{array}$ & $\begin{array}{l}\text { Predicted } \\
\text { TLCO,BL }\end{array}$ & $\begin{array}{l}\text { Observed } \\
\text { TLCO,BL }\end{array}$ & $\begin{array}{l}\text { Observed } \\
\text { TLCO,SL }\end{array}$ & $\begin{array}{l}\text { Ratio } \\
\text { TLCO,SL/TLCO,BL }\end{array}$ & $\begin{array}{l}\text { Ratio } \\
\text { VA,EFF,SL/VA,EFF,BL }\end{array}$ \\
\hline $\begin{array}{l}3 \\
6 \\
7 \\
8 \\
10 \\
12 \\
\text { Mean (SD) }\end{array}$ & $\begin{array}{l}\text { Right } \\
\text { Right } \\
\text { Right } \\
\text { Right } \\
\text { Right } \\
\text { Right }\end{array}$ & $\begin{array}{r}9 \cdot 00 \\
12 \cdot 88 \\
10 \cdot 30 \\
10 \cdot 01 \\
11 \cdot 86 \\
9 \cdot 00\end{array}$ & $\begin{array}{r}6 \cdot 15 \\
15 \cdot 00 \\
12 \cdot 10 \\
7 \cdot 95 \\
11 \cdot 05 \\
9 \cdot 40 \\
10 \cdot 28(3 \cdot 15)\end{array}$ & $\begin{array}{l}4 \cdot 37 \\
8 \cdot 79 \\
6 \cdot 01 \\
4 \cdot 49 \\
5 \cdot 44 \\
4 \cdot 34 \\
5 \cdot 57(1 \cdot 72)\end{array}$ & $\begin{array}{l}0.71 \\
0.59 \\
0.50 \\
0.56 \\
0.49 \\
0.46 \\
0.55(0.09)\end{array}$ & $\begin{array}{l}0.68 \\
0.57 \\
0.53 \\
0.52 \\
0.55 \\
0.55 \\
0.57(0.06)\end{array}$ \\
\hline $\begin{array}{l}1 \\
2 \\
4 \\
5 \\
9 \\
11 \\
\text { Mean (SD) }\end{array}$ & $\begin{array}{l}\text { Left } \\
\text { Left } \\
\text { Left } \\
\text { Left } \\
\text { Left } \\
\text { Left }\end{array}$ & $\begin{array}{l}10 \cdot 17 \\
13 \cdot 75 \\
12 \cdot 77 \\
12 \cdot 59 \\
11 \cdot 02 \\
12 \cdot 33\end{array}$ & $\begin{array}{r}7 \cdot 05 \\
14 \cdot 90 \\
13 \cdot 30 \\
15 \cdot 40 \\
10 \cdot 20 \\
9 \cdot 50 \\
11 \cdot 37(3 \cdot 32)\end{array}$ & $\begin{array}{l}3 \cdot 11 \\
6 \cdot 39 \\
5 \cdot 67 \\
6 \cdot 18 \\
4 \cdot 46 \\
5 \cdot 02 \\
5 \cdot 14(1 \cdot 23)\end{array}$ & $\begin{array}{l}0.44 \\
0.43 \\
0.43 \\
0.40 \\
0.44 \\
0.53 \\
0.44(0.04)\end{array}$ & $\begin{array}{l}0.55 \\
0.47 \\
0.47 \\
0.49 \\
0.53 \\
0.49 \\
0.50(0.03)\end{array}$ \\
\hline
\end{tabular}

Abbreviations and units as in table 1 .

single to both lung alveolar volume and that of single to both lung transfer factor $(r=0 \cdot 81$, $\mathrm{p}<0.001)$.

\section{EFFECT OF OCCLUSION VOLUME}

When one lung was occluded at RV the mean values of VA,EFF,SL, VI,SL, and TLCO,SL of the other were significantly lower $(p<0.001)$ than the values obtained during occlusion at TLC $(2.84 v 3.261,2.18 v 2.541$, and $4.70 v$ $5.51 \mathrm{mmol} / \mathrm{kPa} / \mathrm{min}$, respectively) (table 1 ). The lower VA,EFF, SL during occlusion at RV was not accompanied by an increase in $\mathrm{KCO}, \mathrm{SL}$, nor was there any effect of occlusion volume on RVSB,SL. There was no significant difference between Kco,BL and the two Kco,SL values (table 1, 3rd column). Some subjects noticed an unpleasant feeling in their chest at extreme lung volumes. On three occasions (of 48 in total) the oxygen saturation fell below $90 \%$.

\section{Discussion}

The airway occlusion technique has been described in detail in a previous paper, ${ }^{1}$ which also contains references to earlier studies on unilateral lung function, in particular bronchospirometry. ${ }^{16}$ The latter was used when gas transfer of a single lung was measured for the first time. ${ }^{2}$ In that study the sum of the right and left TLCo,SL was lower than the value for both lungs. Subsequent investigators have applied bronchospirometry and the steady state method and have shown that single lung gas transfer of both healthy and diseased lungs correlated well with the ventilation to each lung. ${ }^{1718}$ In contrast, unilateral pulmonary blood flow had to decrease considerably to affect differential gas transfer. ${ }^{18}$

In this study we occluded the mainstem bronchus on one side at both extreme lung volumes, just before the test gas was inhaled. When one lung was occluded at TLC the mean TLCO,SL and volumes of the other were approximately half the values of both lungs. During occlusion at RV three of the volumedependent properties of the ventilating lung VI,SL, VA,EFF,SL, and TLCO,SL - were significantly lower than during occlusion at TLC. RVSB,SL was independent of occlusion volume, while occlusion did not affect Kco at all. Repeat measurements within a few minutes gave significantly lower values for TLCO,SL and KCO,SL during occlusion at RV.

The lower VA,EFF,SL during occlusion at RV was almost entirely due to the reduced VI,SL. The difference in VI,SL at the two occlusion volumes (mean $0.36 \mathrm{l}$ ) was too large to be explained by a difference in blood volume in the ventilating lung, nor could it be caused by pain during inspiration as this was felt by 
only some subjects. The most likely explanation for the reduced VA,EFF,SL during occlusion at $\mathrm{RV}$ is that the hemithorax on the non-occluded side did not expand maximally. Although chest wall movement was not measured, it is conceivable that the hemithorax on the occluded side barely increased its dimensions which would also affect the expansion of the other.

The lower TLCo,sL during occlusion at RV is best explained by the concurrent decrease in VA,EFF,SL ${ }^{36-8}$ which occurred in all but one subject. However, in contrast to the usual case, ${ }^{8}$ TLCO,SL decreased more (15\%) than VA,EFF,SL $(13 \%)$, suggesting that other factors may have contributed to reduce TLCO,SL during occlusion at RV. The transfer of carbon monoxide is inversely related to the tension of alveolar oxygen during breathholding. ${ }^{219}$ If the shortlasting occlusion led to different alveolar oxygen tensions at the two occlusion volumes, the lower tension would be expected to occur during occlusion at RV. This would increase gas transfer, not decrease it. Intra-alveolar pressure during breathholding also has an inverse effect on gas transfer ${ }^{20}$ which may have decreased if the subjects relaxed against the closed valve during breathholding. A shift in pulmonary blood flow towards the occluded deflated lung, due to the high negative pressure on that side during inspiration, ${ }^{20}$ could in theory decrease capillary blood volume in the ventilating lung and hence lower TLCO,SL.

Several investigators have found an inverse relation between alveolar volume and Kco. ${ }^{36910}$ This is most pronounced at volumes below $80 \%$ of TLC. Above this volume the relation is constant. ${ }^{3}$ In our study the mean VA,EFF,SL during occlusion at RV was $87 \%$ of that obtained during occlusion at TLC. The latter VA,EFF,SL was probably close to the TLC of the non-occluded lung. The decrease in VA,EFF,SL from occlusion at TLC to occlusion at RV (mean 0.42 l) was possibly too small to affect Kco,sL. Alternatively, a volume-dependent increase in the latter may have been counteracted by other factors as suggested above.

Unilateral volumes and TLCO,SL were as expected during occlusion at TLC - that is, half the values of both lungs. A normal expansion of the ventilating lung is necessary to obtain the "true" TLCO,SL. This seems to be accomplished only if the other lung is occluded at or near TLC. Because of our previous results, ${ }^{1}$ we had expected to find the larger RVSB,SL during occlusion at TLC. In that study we measured volumes by the standard gas dilution technique. In the present study, however, a single breath estimate of VA,EFF,SL was used to calculate RVsB,SL. The latter is underestimated if helium is incompletely diluted during breathholding. ${ }^{21}$ At its preinspiratory volume the ventilating lung was probably compressed by the hyperinflated lung when the latter was occluded at TLC due to the pressure gradient across the mediastinum. In contrast, it was presumably configured normally before inhalation of the test gas when occlusion took place at RV. A difference in the compression of, and hence extent of, airway closure in the ventilating lung before the test gas was inhaled may have led to a difference in distribution of $\mathrm{VI}_{\mathrm{I}} \mathrm{SL}^{22}$ resulting in an underestimated RVSB,SL during occlusion at TLC.

Serial measurements increase back pressure of capillary carbon monoxide and reduce the number of available binding sites at the haemoglobin molecule. ${ }^{23}$ The concurrent reduction in TLCO is approximately $1 \%$ for each percentage of carboxyhaemoglobin, ${ }^{23}$ and is obviously too small to explain the significantly lower second value of TLCO,SL and KCO,SL during occlusion at RV. A full inspiratory manoeuvre followed by breathholding at TLC induces hysteresis of the alveolar membrane. ${ }^{15}$ This persists for at least seven minutes and leads to an immediate but temporary increase in gas transfer, but only if the subsequent alveolar volume is $85 \%$ of TLC. ${ }^{24}$ As this happened to be the breathholding volume during occlusion at RV in this study, we speculated that the first replicate might be spuriously high due to alveolar hysteresis induced by the preceding test. However, the four subjects in whom the very first duplicate measurements were made during occlusion at RV also had a lower second value. Furthermore, the first TLCO,SL during occlusion at RV did not seem unduly high compared with the value at TLC, which was half that of both lungs. We are therefore not convinced that alveolar hysteresis can explain the systematic error that we observed.

The repeatability of single breath single lung gas transfer measurements was not as good as that of whole lung variables, and could in this study only be estimated during occlusion at TLC. The mean TLCO,sL of the right lung was $55 \%$, and that of the left $44 \%$ of the value for both lungs, figures that compare well with the size of the two lungs. ${ }^{25}$ Although the ratio of single gas transfer to that of both lungs varied considerably between subjects, as did the ratio of VA,EFF,SL to VA,EFF,BL, our findings may give useful additional information, in particular in patients with lungs that are thought to differ markedly in their function and in whom bronchoscopy is considered for other reasons.

In summary, shortlasting occlusion of one mainstem bronchus permits measurement of the single breath gas transfer of the other, but the volume at which one lung is occluded should be at or near TLC. Occlusion at RV probably prevents the expansion of both the occluded and non-occluded hemithorax, resulting in lower transfer values. Moreover, occlusion at RV leads to a significantly lower second value when duplicate measurements are performed; the reason for this is not known.

The technical assistance of Inger Hem, Else-Margrethe Blix and Christin Hornmoen is highly appreciated. The study was supported financially by a grant from Glaxo Norway AS.

1 Johansen B, Bjørtuft $\varnothing$, Boe J. Static lung volumes in healthy subjects assessed by helium dilution during occlusion of one mainstem bronchus. Thorax 1993;48:381-4.

2 Ogilvie CM, Forster RE, Blakemore WS, Morton JW. A gilvie CM, Forster RE, Blakemore WS, Morton JW. A
standardized breath holding technique for the clinical measurement of the diffusing capacity of the lung for carbon monoxide. $f$ Clin Invest 1957;36:1-17.

3 McGrath MW, Thomson ML. The effect of age, body size and lung volume on alveolar-capillary permeability and diffusing capacity in man. $\mathcal{F}$ Physiol (Lond) 1959;46:57282. 
4 Teculescu DB. Validity, variability and reproducibility of single breath total lung capacity determinations in norma single breath total lung capacity determinations in nor
subjects. Bull Eur Physiopathol Respir 1971;7:645-58.

5 Cotton DJ, Prabhu MB, Mink JT, Graham RL. Effects of ventilation inhomogeneity on DLCo ${ }^{\mathrm{SB}}-3 \mathrm{EQ}$ in norma subjects. F Appl Physiol 1992;73:2623-30.

6 Cadigan JB, Marks A, Ellicott MF, Jones RH, Gaensle EA. An analysis of factors affecting the measurement of pulmonary diffusing capacity by the single breath method. $\ngtr$ Clin Invest 1961;40:1495-514.

7 Hamer NAJ. Variations in the components of the diffusing capacity as the lung expands. Clin Sci 1963;24:275-85.

8 Rose GL, Cassidy SS, Johnson RL Jr. Diffusing capacity at different lung volumes during breath holding and redifferent lung volumes during breath

9 Stam H, Versprille A, Bogaard JM. The components of the carbon monoxide diffusing capacity in man dependent on alveolar volume. Bull Eur Physiopathol Respir 1983;19: 17-22.

10 Lipscomb DJ, Patel K, Hughes JMB. Interpretation of increases in the transfer coefficient for carbon monoxide (Tlco/VA or Kco). Thorax 1978;33:728-33.

11 Quanjer PH (ed). Standardized lung function testing. Clin Respir Physiol 1983;19(Suppl 5):45-51.

12 Quanjer PH (ed). Standardized lung function testing. Clin Respir Physiol 1983;19(Suppl 5):39-44.

13 Horsfield K, Cumming G. Morphology of the bronchial tree in man. $\mathcal{F}$ Appl Physiol 1968;24:373-83.

14 Jones RS, Meade FA. Theoretical and experimental analysi of anomalies in the estimation of pulmonary diffusing capacity by the single-breath method. $Q \mathcal{F}$ Exp Physio 1961;46:131-43.
15 Cassidy SS, Ramanathan M, Rose GL, Johnson RL Jr. Hysteresis in the relation between diffusing capacity of the lung and lung volume. $\mathcal{F} \mathrm{Appl} P$ hysi

16 Jacobaeus HC, Frenckner P, Bjørkman S. Some attempts at determining the volume and function of each lung separately. Acta Med Scand 1932-33;79:174-207.

17 Turino GM, Brandfonbrener M, Fishman AP. The effect of changes in ventilation and pulmonary blood flow on the diffusing capacity of the lung. $\mathcal{F}$ Clin Invest 1959;38 1186-201.

18 Lopez-Majano V, Dutton RE. Factors influencing the diffusing capacity of each lung. Respiration 1972;29:427-36.

19 Canner RA, Crapo RO. The relationship between alveolar oxygen tension and the single-breath monoxide diffusing oxygen tension and the single-breath monoxide
capacity. Am Rev Respir Dis 1986;133:676-8.

20 Cotton DJ, Mink JT, Graham BL. Effect of high negative inspiratory pressure on single breath CO diffusing capacity. Respir Physiol 1983;54:19-29.

21 Van Ganse W, Comhaire F, van der Straeten M. Residual volume determined by single breath dilution of helium a various apnoea times. Scand f Respir Dis 1970;51:73-81.

22 Crawford ABH, Cotton DJ, Paiva M, Engel LA. Effect of airway closure on ventilation distribution. $\mathcal{f}$ Appl Physiol 1989;66:2511-5.

23 Frans A, Stanescu DC, Veriter C, Clerbaux T, Brasseur L Smoking and pulmonary diffusing capacity. Scand $\mathcal{F}$ Respir Smoking and pulmo

24 Lebecque P, Mwepu A, Veriter C, Rodenstein D, Nemery B, Frans A. Hysteresis of the alveolar capillary membrane in normal subjects. $\mathcal{F}$ Appl Physiol 1986;60:1442-5.

25 Thurlbeck WM. Post-mortem lung volumes. Thorax 1979 34:735-9. 